\title{
Amor y autoridad. Ejercicios legítimos del poder de las policías mujeres en su trabajo.
}

\author{
Sabrina Calandrón* \\ ${ }^{*}$ CONICET, Universidad Nacional de Quilmes y Universidad Nacional de San \\ Martín. E-mail: sabrinacalandron@gmail.com
}

RMA

Antropología Social

\begin{abstract}
Resumen
Pensar los modos de ejercicio de la autoridad por parte de las mujeres en la policía bonaerense lleva a reflexionar sobre la asociación entre las cualidades y relaciones personales y el poder formalizado puesto en escena en los espacios laborales. Los vínculos, sentimientos y experiencias afectivas introducen orientaciones particulares al devenir de la profesión policial de las personas, especialmente para las mujeres. Ese plus amoroso es vivido, algunas veces, como una obligación personal y, otras, como una estrategia que permite capitalizar las habilidades laborales.

El análisis de esta asociación particular es un aporte al estudio de las significaciones y experiencias alrededor de los complejos procesos de ingreso y jerarquización de mujeres en las policías. Porque además de exigir enérgicas adaptaciones a las policías mujeres, provocó modificaciones en la forma de ejercer la profesión más allá del género. Este artículo no pierde de vista cómo se conjugan clivajes sociales diferentes en la dinámica de las relaciones de poder. Los datos analizados han sido construidos con trabajo de campo etnográfico en comisarías de la Policía de la Provincia de Buenos Aires.
\end{abstract}

Palabras claves: autoridad; policía; erotismo; afectividad; género.

Love and authority. Legitimate power exercise of police women at work

\begin{abstract}
To think about the ways that women police officers from the Buenos Aires police force exercise authority leads to a reflection of the association between personal qualities and the relationships and institutionalized power taking place in workplaces. Ties, feelings and affective experiences introduce specific guidelines to the future of the police profession, especially for women. This extra love is experienced sometimes as a personal duty and others as a strategy to capitalize job skills.

The analysis of this particular association contributes to the study of meanings and experiences around the complex process of entry of women into the police force; [semicolon] a process that, [comma] in addition to demanding energetic adaptations from women police officers, it also brought about changes in the way of practicing the profession aside from gender issues. This article takes account of how social differences combine in dynamics of power relations. The data analyzed derive from ethnographic fieldwork in police stations of the Buenos Aires police force.
\end{abstract}

Keywords: authority; police; eroticism; affectivity; gender.

Dos factores provocaron el supuesto, pocas veces comprobado, de que las mujeres que trabajan en la policía ocupan los lugares más bajos en la escala de poder y sufren las discriminaciones más atroces (Arteaga Botello, 2000; Suárez De Garay, 2006). El primero de ellos nos remite a la historia de las instituciones policiales, en esta oportunidad me dedicaré a la Policía de la Provincia de Buenos Aires, compuesta inicialmente sólo por varones -que aún hoy retienen la abrumante mayoría de las plazas más altas en la jerarquía formal- pero una de las fuerzas pioneras en incluir el reclutamiento de mujeres ${ }^{1}$. El segundo supuesto

\footnotetext{
1 En diciembre de 2010 ascendió, por primera vez en la historia de la PPBA, una mujer al grado más alto de la institución: Comisario General. Es una mujer que ocupa uno de los doce lugares que se renuevan cada, aproximadamente, dos años. Sobre la formación y experiencias
}

remite a una discusión epistemológica clásica de las ciencias sociales, en la que la antropología ha avanzado hacia algunos acuerdos. Los estudios sobre la policía en la región han subrayado el carácter condicionante de la estructura, incluyendo allí las prácticas reiteradas y los sentidos compartidos en extenso por los individuos que la componen. Y, a causa de lo anterior, poco espacio ha quedado para el análisis de los procesos voluntarios en los que los sujetos eligen estratégicamente cómo actuar. Escasos y recientes trabajos dejaron de lado la insistencia en encontrar la fuerza estructural, incluso la maniobra de descubrir la omnipotencia de la estructura en los discursos personales, para mostrar además las respuestas,

del primer cuerpo de Policía Femenina de la PPBA, en el año 1947, véase Calandrón y Galeano (en prensa). 
resistencias y apropiaciones que la estructuración sufre (Garriga Zucal, 2010; Renoldi, 2007 y 2010; Frederic, 2008).

Detrás de este segundo supuesto, rige la premisa de que el poder es un bien distribuido exclusivamente desde la institución, o por los individuos que hacen eco de esa tarea corporativa y formalizada. Para discutir esa hipótesis es preciso señalar los aportes de algunas teorías de género desarrolladas desde hace más de tres décadas. Particularmente Joan Scott definió el género como "un elemento constitutivo de las relaciones sociales basadas en las diferencias entre los sexos, en tanto forma primaria de relaciones significantes de poder" (Scott 1996: 265). En este sentido, para comprender esas relaciones significantes de poder es necesario apuntar al tipo de articulación entre las dimensiones simbólica, normativa, institucional y subjetiva. Manteniendo como principio de análisis esa profunda alianza (referida en el concepto de género de Scott) de la diferencia entre los sexos con las relaciones de poder, este trabajo describe formas concretas en que el poder se construye y legitima en las interacciones cotidianas. De modo que incluimos saberes y destrezas informales y diversas que escapan al acto formal de la obtención de "jinetas"2. Esas habilidades se componen, en los casos aquí seleccionados por su densidad analítica, por la capitalización del tiempo invertido en la comisaría, el cuidado del espacio, las relaciones amorosas que permiten permisos y complicidades y las capacidades intelectuales adquiridas en otros ámbitos laborales o educativos ${ }^{3}$.

Finalmente, en la lógica de ese supuesto inicial, las mujeres se encontrarían frente a dos caminos. O bien someterse a condiciones laborales desfavorables pasivamente, o bien optar por alejarse del aparente colectivo sumiso compuesto por las mujeres, adquiriendo rasgos de masculinidad que les permitirían actuar, en algunas circunstancias, como si fueran varones. En un trabajo precursor sobre policías mujeres, Susan Martin indicaba la inevitabilidad de estos dos caminos: desfeminización o desprofesionalización (Martin, 1980:186). Estudios posteriores reafirmaron la hipótesis de Martin (Hagen, 2005), y explicaron tal fenómeno en el pasado masculino del trabajo policial y la constante producción de una masculinidad que cuestiona la presencia de mujeres. En este punto, el diálogo con las revisiones de las teorías feministas elaboradas a partir de los años 1990 resulta propicia para complejizar la noción de género que incluye esa afirmación contundente de Susan Martin. A pesar de que se trata de un largo debate, quiero destacar el abandono de nociones normativas del género y la emergencia de un concepto que incluye identidades

\footnotetext{
2 Las "jinetas" son elementos que componen el uniforme reglamentario, se colocan sobre los hombros y exhiben (con rayas y estrellas) el grado jerárquico de quien las porta.

3 A lo largo del texto, utilizo comillas para citar expresiones nativas registradas en el trabajo de campo, las cuales tienen un significado particular en ese contexto.
}

que pueden ser cambiantes, múltiples y contradictorias. Andrea Cornwall y Nancy Lindisfrarne dirigieron una conocida publicación donde no sólo discutieron el sentido unívoco de la masculinidad sino que, en los artículos que incluye esa compilación, mostraron los diferentes modos en que la masculinidad aparece y opera en la socialización (Cornwall y Lindisfrarne, 1994). Esta misma estrategia teórica es útil para entender las femineidades en su complejidad, y es propicia para afirmar que la feminización o desfeminización de una profesión -o de las personas que la desarrollan- es un proceso controvertido, activado en un espacio de disputa. Finalmente, con una gran lucidez, nos recuerda que aquellos rasgos o atributos que son considerados como "femeninos" en un espacio social, pueden no serlo en otro ${ }^{4}$.

Con los datos empíricos que en este trabajo presento, mostraré tanto las exigencias que las costumbres y opiniones socialmente difundidas imponen a las mujeres en la policía, como las respuestas a esas exigencias que ellas efectúan en la comisaría en la que realicé el estudio. Ver también estas acciones donde se aprecian (enfrentan o modifican) las interpretaciones subjetivas sobre procesos más generales, se apoya en la concepción de los/as nativos/as como actores estratégicos que dirimen y eligen entre distintas posibilidades con algún nivel de conciencia. Si bien las condiciones institucionales, por la historia y por la débil presencia de mujeres en los grados más altos de la jerarquía de la policía bonaerense, las posicionan en desventaja, es importante ver las estrategias informales con las que se combina esta lógica. En la convivencia de esas dinámicas distintas, puede verse que los individuos no aceptan sencilla y pasivamente esa desventaja inicial, sino que la ponen en discusión.

El título de este artículo propone una asociación entre el amor y la autoridad, sugiriendo el uso de estrategias informales, cuyo contenido son los atributos y cualidades personales, para la construcción de legitimidad en el ejercicio del poder. Siguiendo la concepción clásica y mínima de poder hecha por Max Weber, entenderemos por él la posibilidad de imponer la propia voluntad al interior de una relación social (Weber, 1996) que, investida de aceptación por quienes son objetivo de esa relación, se convierte en autoridad. El concepto amor no remite, en este caso, al amor romántico que hace énfasis en las emociones y fundamenta la idealización del matrimonio. Tomo el amor como un conjunto de sentimientos, emociones y actitudes que incluyen apego (entre las personas y con las cosas), confianza, afectos, afinidades y comprensiones compasivas. Un sentimiento de cercanía que puede traducirse y concretarse de formas comunicativas muy diferentes. Los encuentros sexuales, cuidados serviciales, complicidades amistosas, ayuda, diálogos gratos, amor incondicional (aquel que se ofrece

\footnotetext{
4 Retomando el desarrollo de Pierre Bourdieu (Bourdieu, 1998), para analizar una problemática de investigación es necesario diferenciar los sentidos de la "femineidad" que tienen disponibles las/os investigadoras/es, de aquellas nociones válidas para los/as nativos/as.
} 
sin esperar nada a cambio) serán tomados en este trabajo como experiencias relativas a ese sentimiento amplio que participa en la convivencia laboral y los poderes puestos en juego.

En este sentido, los datos empíricos utilizados para este texto fueron construidos a partir del trabajo de campo etnográfico realizado en una comisaría de la Policía de la Provincia de Buenos Aires, situada en una localidad del conurbano bonaerense. Este artículo es producto, casi en su totalidad, de observaciones y entrevistas durante las que presencié los acercamientos y diálogos que se daban entre quienes se desempeñaban, en ese momento, en la comisaría. De modo que los temas subrayados son aquellos que fueron destacados en ese espacio laboral por los agentes policiales, indudablemente, tamizados e interpretados con mis herramientas analíticas.

\section{La cuestión de las mujeres en las "reformas" 5 policiales}

Sin desentonar con las inclinaciones clásicas que las reformas policiales han tenido en Argentina, las llevadas adelante en las décadas de 1990 y 2000 estuvieron dirigidas principalmente al campo de la formación, los sistemas de ingreso y la organización interna del personal que se encontraba en actividad laboral (particularmente asociada a la organización jerárquica). La ley 13.201 de personal -sancionada y reglamentada en noviembre de 2004- eliminó la antigua distribución entre oficiales y sub-oficiales, que era identificada por los/as gestores/ as de las reformas como un símbolo antidemocrático y conservador ${ }^{6}$. Fue entonces que el sistema de ingreso dejó de estar concentrado en las dos instituciones que funcionaban incansablemente desde la década de $1940^{7}$ y se diseminó entre los casi once Institutos de Formación Policial instalados en ciudades del interior de la provincia de Buenos Aires.

El nuevo esquema de ingreso incluyó tanto modificaciones en los programas de estudio y especialidades, como la multiplicación de la cantidad de personal incorporado: los/as 500 oficiales que se sumaban anualmente a la policía pasaron a convertirse en aproximadamente 5000 a partir del año 2004, de los/as cuales casi la mitad eran

\footnotetext{
${ }^{5}$ La "reforma" refiere aquí a una etapa caracterizada por un conjunto de cambios organizativos y normativos, que se identifica especialmente con el gestión del Ministro de Seguridad de la provincia de Buenos Aires León Arslanián, pero incluye -para los/as nativos/as- diferentes sentidos. Mientras algunos destacan los cambios en las políticas educativas comenzadas a principios de la década de 1990, otros remarcan las modificaciones en la Ley de Personal Policial del año 2004. Por ello, la expresión de "reforma" indica una temporalidad específica de acuerdo a la perspectiva de los actores, sobre este asunto véase Bover y Calandrón (2009).

6 Esta política fue revisada y reemplazada por otra en el año 2009, cuando a partir del mes de julio se implementó la nueva Ley de Personal Policial que volvió a establecer una distinción estamental entre sus trabajadores/as.

7 Se trata de la Escuela de Oficiales "Juan Vucetich" y Escuela de suboficiales y agentes "Agente Rosendo Matías".
}

mujeres ${ }^{8}$. Este último dato es relevante a los fines del presente trabajo porque la elevación en la cantidad de mujeres en la policía se convirtió en un tema de diálogo, disputa y enojos entre miembros de la policía. En el año 2004 el 9\% del total del personal en actividades policiales eran mujeres, mientras que hacia finales del 2007 lo eran el $22 \%$. Para el equipo de funcionarios/as del Ministro de Seguridad de la Provincia de Buenos Aires, León Arslanián (funcionario de ese cargo durante los años 1998-1999 y, más tarde, 2004-2007), el cada vez mayor número de mujeres debía acompañarse por modificaciones de la normativa que hasta ese momento había limitado su posibilidad de ascenso y restringido el desarrollo de sus actividades laborales. Las normas reglamentarias que se eliminaron fueron las que impedían a las mujeres acceder a los grados más altos en la jerarquía y aquellas que establecían una permanencia mayor (de las mujeres respecto de los varones) en cada grado para lograr el ascenso. Así es como estaba en funcionamiento un método de descalificación genérica en el plano formal de la fuerza policial, ser mujer implicaba en sí mismo un obstáculo para avanzar en cadena de mando.

En materia del quehacer cotidiano, las "reformas" eliminaron algunos preceptos que determinaban la imposibilidad de que las "unidades mínimas operativas" estén compuestas sólo por mujeres ${ }^{9}$. Incluso los servicios de la policía adicional ( $P O / A d)$, aquellos servicios de seguridad brindados a entidades públicas o privadas que son pagados a quienes los realizan por fuera de su salario, estaban regidos por esa normativa que habilitaba la posibilidad de que el servicio sea cubierto por dos varones (o una mujer y un varón), pero en ningún caso por dos mujeres ${ }^{10}$.

El cambio cuantitativo en la composición del personal, ocurrido progresivamente desde el año 2004, es un tema de diálogos entre quienes trabajan en la institución, sobre el que destacan debilidades y fortalezas para las intervenciones policiales. Para dimensionar las proporciones, consideremos que en una comisaría en la que en el año 2003 trabajaban unas seis o siete mujeres -del total de ochenta y cinco personas- pasaron a hacerlo, hacia el 2006, unas veinte. Esta circunstancia amplió y renovó el abanico de roles posibles de ser cubiertos por mujeres, que "antes" estaban más limitados porque muchos puestos se reservaban para varones o porque, por baja presencia de cupo femenino, se las aprovechaba en tareas donde eran irremplazables (como requisa a otras mujeres), de modo que se evitaba afectarlas a quehaceres generales.

\footnotetext{
8 Datos extraídos de Plan de Reformas de las Policías. Resultados de Gestión 2004-2007, León Carlos Arslanián, Ministerio de Seguridad de la Provincia de Buenos Aires, 2007

9 Las "unidades mínimas operativas" son los equipos de personas indispensables para realizar determinada tarea. En la mayoría de los casos se trata de dos personas.

10 Se trata de la ley 7.065 y su modificación 10.990, reemplazada por la 13.942 de la Policía Adicional.
} 
Actualmente, la multiplicación de actividades que las mujeres hacen en una comisaría abre la proyección profesional femenina de las recién llegadas a nuevas opciones. Las nuevas cohortes suponen que "antes" estaban obligadas a hacer únicamente dos o tres actividades de las que era difícil escapar u oponer resistencia, y "ahora" tienen más opciones entre las que elegir. Quebrar algunos de los parámetros que hacían de límites virtuales a las funciones de las mujeres es un proceso que se le adeuda, en parte, a esa relación numérica, pues están a cargo de responsabilidades variadas, y en parte, a un ambiente más dispuesto -para varones y mujeres- a escuchar las demandas de quienes trabajan allí. Se trata del reconocimiento de un proceso de mayor permisibilidad y negociación entre jefes y subalternos/as, que para algunos de sus miembros deterioró los valores policiales y para otros/as le otorgó profesionalismo al oficio.

\section{Tiempo, espacio y autoridad}

En la comisaría donde realicé el estudio, cada fin de año se confecciona una lista del personal que está en condiciones de ascender en la escala jerárquica. La lista se completa y edita durante varios días, es producto de diferentes criterios que se superponen y a veces se contradicen. En la evaluación de cada policía se tiene en cuenta la cantidad de años que han pasado desde su último ascenso, la edad (por ejemplo, el ascenso antes de la jubilación es preciado, pues determinará el monto de dinero percibido cada mes hasta la muerte), el desempeño laboral (medido por los méritos, faltas y presentismo) y la formación académica.

Úrsula ${ }^{11}$, sargento a cargo de la Oficina de Personal de la comisaría, se encarga de elevar la versión final de la lista a la Jefatura Departamental, desde donde es enviada al Ministerio de la provincia -según se espera y se hace usualmente- sin modificaciones. De acuerdo a lo ocurrido los años anteriores, las personas de la comisaría esperan que en los meses siguientes comiencen a llegar los nombramientos de las nuevas jerarquías con pocas modificaciones respecto a la propuesta inicial que partió de la comisaría, apenas algunos nombres que se habrán omitido -y no tendrán el reconocimiento esperado- y uno o dos que estarán allí a pesar de no haber sido propuestos originalmente. Esos mínimos desajustes en relación a lo planificado causa, por algunos días, una buena conmoción entre el personal $y$, dependiendo de la naturaleza de esas incompatibilidades, se buscan explicaciones, justificaciones o se labran quejas informales.

La elaboración de esa preciada lista incluye gestos administrativos parecidos a otras tareas típicas de la Oficina de Personal (como la indicación del personal para asistir al reentrenamiento, los pagos de asignaciones familiares o la concesión de vacaciones), pero a diferencia de esos

\footnotetext{
${ }^{11}$ Los nombres que utilizo son ficticios para preservar la identidad de las personas.
}

trámites, los ascensos cuentan con un valor supremo debido a que cristalizan reconocimientos económicos y simbólicos para los individuos. El grado jerárquico es una marca de distinción que se exhibe constantemente en la persona del/la policía, lo lleva en su ropa, acompaña su nombre cuando firma y se utiliza, en relaciones más distantes, para dirigirse a una persona en reemplazo de su nombre. Es por esto que a la elaboración de esta lista la precede una silenciosa competencia interpersonal para tener un lugar allí, lugar que no siempre es entendido del mismo modo. Hay quienes creen que el mérito que impulsa un ascenso es la lealtad hacia las autoridades, la aceptación de las reglas que imponen y el cumplimiento de las pautas de trabajo establecidas por ellos. Por otra parte, están aquellos/as que entienden que el ascenso se deriva de los sacrificios hechos por el oficio; también se trata de un apego, pero hacia "la policía" como un sujeto más abstracto. Finalmente, muy pocos/as esperan que sea un reconocimiento a la formación académica en institutos policiales o universitarios.

Es sabido, en el ámbito de la comisaría, que Úrsula no es sólo un eslabón que materializa decisiones enviadas por otros, sino que goza de tanta confianza del comisario como para ser parte activa del proceso de toma de decisiones. Amparada en sus nueve años en la comisaría en la que está actualmente, considera que "ha visto pasar a varios jefes", experiencia que muestra su capacidad para mantenerse allí a pesar de la habitual circulación hacia/ desde otras dependencias. Tiene unos 45 años de edad, (más de quince años de antigüedad) y es reconocida como una mujer "adulta" con experiencia de trabajo, diferente a las mujeres más "jóvenes" ingresadas como efecto de las reformas.

El tiempo de experiencia es un capital preciado en el desarrollo del trabajo, aunque no se trata sólo de un acopio de años de antigüedad, sino de la capacidad para generalizar la propia percepción de esa temporalidad (que incluye la descripción de la historia reciente de la comisaría asociada a los eventos de la vida personal). El conocimiento del territorio en el que trabajan las fuerzas policiales es un proceso que se interrumpe $y$, en muchas oportunidades, vuelve a iniciarse cada vez que los/as policías son trasladados/as hacia zonas nuevas. Esos traslados son vividos por los miembros de la policía cada, aproximadamente, dos o tres años (esto es más estricto entre policías de la oficialidad que suboficiales). Por eso, para los jefes de esta comisaría, Úrsula es una informante clave para aprender los detalles de la jurisdicción, los problemas delictivos particulares y las personas que actúan allí. Porque esa es la información que Úrsula sabe recavar e interpretar desde hace tiempo, es el anclaje con el territorio y la "llegada" a los vecinos.

La lógica de la movilidad presente como experiencia del pasado, aparece también como proyección hacia el futuro: la sargento supone que en poco tiempo verá irse a los actuales jefes y ella continuará en su lugar. 
Estratégicamente, presenta su propia estabilidad dentro de la lógica temporal de la comisaría como un valor apreciable y útil para llevar una adecuada dirección de la dependencia. Esto se refleja cuando recuerda cómo ella presentó los jefes para los/as vecinos/as y los consejos aportados acerca de cómo "hacerse conocido" en el barrio y lograr apoyo social.

Al cruzarse en un pasillo, Úrsula le avisa al titular de la comisaría que "Andrea, de la departamental, ya me pidió la lista, hay que ver a quién ponemos. Tiene que estar en unas semanas porque después, a último momento, hay que andar a las corridas". El capitán Pellegrini sigue su marcha dando a entender con un ínfimo ademán que comprendió el mensaje. Al contrario de lo que yo hubiese esperado para tamaña tarea, la discusión no se limitó al secreto de las oficinas privadas, sino que los lugares más públicos fueron escenario del disimulado debate. Pasillos, patio y comercios públicos se convirtieron en el terreno donde intercambios encubiertos de apellidos se contestaron con gestos de desacreditación o palabras de ironía, métodos más utilizados para dar la baja a posibles merecedores/as.

La cocina se volvió propicia para continuar la discusión sobre los ascensos, dado que diariamente Úrsula almuerza allí acompañada por los jefes de la comisaría. Ella invierte dedicación para que la comida sea posible, buscando y preparando alimentos, haciendo compras y pidiendo, entre los/as vecinos/as, aquellos utensilios que no se encuentran en la comisaría. Es la única persona que tiene acceso a todos los muebles (cerrados con llaves y cadenas) y que guarda, pareciera, sus propias pertenencias allí. Durante la comida del mediodía se informan las últimas novedades y se ponen en juego opiniones acerca del desenvolvimiento del personal a través de narraciones de un suceso (con sus múltiples versiones e interpretaciones), hipótesis acerca de cómo debería haber actuado el o la policía y propuestas para solucionar problemas diarios menores.

Desde la perspectiva de jefes, compañeros/as y la propia, Úrsula ocupa un lugar preponderante en la dependencia, posible de ser apreciada de manera nítida en muchas situaciones, como la siguiente:

El Turco insiste para que yo entre a tomar mates y a charlar a la oficina. Cuando me voy acercando a la puerta, escucho que hay varias personas conversando. Está Nora sentada frente a su computadora, fumando y gritando como de costumbre. La teniente Fanny y el Turco están parados y apoyados contra la pared; el capitán Barragán está sentado en un costado. Entro y saludo a todos. Viene la teniente Adriana Ordóñez con un papelito y se queda parada cerca de la puerta, en la oficina no cabe una persona más. Nora pregunta para todos cuántos detenidos hay "al final", porque ella encargó la comida.
Turco: Son como diecinueve.

Nora: ¿Me estás jodiendo? Pedí diecisiete viandas, pedí dieciséis y me trajeron dieciséis y una ${ }^{12}$.

Turco: Pero anoche trajeron como a tres [detenidos] más.

Barragán: Había trece, y anoche trajeron tres más, pero no sé si se quedan o se van. Así que son trece y tres.

Nora: Pero tengo que volver a llamar, ya pedí para la noche.

Barragán: Dejá así nomás, que coman lo que haya. Nora: Vos, Fanny, estuviste ahí adentro fichando [hoy fichó a todos los detenidos], ¿cuántos había? Fanny: Qué sé yo, me parece que eran dieciocho y dos más. No me acuerdo.

Nora: ¡Boludo, que alguien le pregunte al oficial de servicio, nadie sabe nada acá!

Turco: No, sí, son dieciséis y tres más que trajeron. En ese momento pasa Úrsula hacia la Oficina de Operaciones y Nora le grita: "Úrsula, ¿cuántos detenidos hay? Tengo que pedir la comida". Úrsula confirma serenamente que hay quince adentro, $y$ tres aprehendidos que bajaron anoche, pero que ahora van al juzgado y cuando vuelvan le dan la libertad a uno, entonces van a quedar dos: "así que pedí diecisiete y uno más". Nora toma su teléfono Nextel, habla con una mujer y le pide el número correcto: "diecisiete y una". ${ }^{13}$

Úrsula no está en un grado jerárquico alto, sargento es el segundo de los nueve escalones que componían el conjunto total de ascensos. Su ingreso lo hizo por el escalafón de suboficiales, distinción basada en una reglamentación que si bien no regía formalmente durante el tiempo en que hice el trabajo de campo, continuaba teniendo efectos prácticos. Lo que se demuestra, por ejemplo, en que sigue siendo uno de los criterios a la hora de dividir tareas ${ }^{14}$.

En la misma línea que la afirmación anterior, el cargo que Úrsula cumple dentro de la dependencia tampoco es un mecanismo de concentración natural de poder, como ocurre con los cargos de "oficial de servicio", "jefe de calle" o "encargado de tercio". Esos son puestos

\footnotetext{
12 La "una" restante es para quien cubre el puesto de "imaginaria calabozo", ubicado dentro del recinto donde están los detenidos. Generalmente la persona de ese puesto no come esa vianda, por lo que la utilizan de porción extra por si llega un nuevo detenido justo en ese momento o se realizó mal la contabilización de personas detenidas.

13 Este extracto y todos aquellos que aparezcan de aquí en adelante como párrafo aparte y sangría han sido tomados de los registros de campo. Les introduje algunas correcciones mínimas para facilitar su comprensión

14 En el momento en que yo hacía el trabajo de campo, estaba en vigencia la ley 13.201 -citada anteriormente- de personal policial que ordenaba las jerarquías del siguiente modo (comenzando por el lugar más bajo): oficial, sargento, subteniente, teniente, teniente primero, capitán. Por encima de estas categorías afectadas a las tareas operativas, están las encargadas de la conducción a nivel departamental o ministerial: inspector, comisionado y superintendente.
} 
donde la tarea principal es la distribución, manejo y responsabilidad de personal y la toma de decisiones a nivel de la organización del trabajo para la comisaría. El de ella es un cargo de los llamados "administrativos", porque se desarrolla dentro del edificio policial e implica trámites estandarizados que deben ser aprobados por una instancia burocrática superior (siempre dedicados a las personas que tienen vínculo laboral con la policía y no con "el público" en general).

A pesar de que formalmente ni del cargo ni del grado de Úrsula se desprende un cúmulo de poder institucional, en las relaciones personales su palabra garantiza un alto nivel de confianza. Pero, aún así, aquí falta un detalle primordial de las tareas laborales y privadas de este lugar: "Úrsula vive en la comisaría". En un principio estuve convencida de que la expresión se trataba sólo de un eufemismo con el que se subrayaba el trabajo a tiempo completo, la entrega y la constancia. Y aunque eso no sea falso, lo que me estaban tratando de indicar es que la sargento ha hecho del espacio de trabajo su casa, de la oficina de administración su habitación, y de la cocina su cocina. Esta situación es así desde hace tres años, cuando por una reconfiguración de su vida familiar y sus proyectos a mediano plazo (armar una hogar propio para vivir) dejó la vivienda materna parcialmente e intentó acumular unos ahorros que le permitieran el posterior despegue. La lealtad hacia los jefes que estaban en ese momento y la gran cantidad de tiempo de trabajo que invertía en la comisaría le permitieron establecerse, temporalmente, allí.

Este escenario, que para mí resulta llamativo e inesperado, es tomado como un hecho inusual (no todos/as viven en la comisaría), pero que goza de cierta naturalidad gracias a una serie de elementos que veremos a continuación. El cambio producido entre el antes y el después de estar instalada en la comisaría no fue lo suficientemente brusco en la vida diaria del espacio. "Antes" pasaba casi tanto tiempo en su trabajo como después de haberse mudado allí, y esto se conecta con lo bien visto que está y lo común que es dedicar jornadas completas a la policía. Quien invierte mucho tiempo en el trabajo es considerado/a, por jefes y compañeros/as, como alguien "con vocación", que ama lo que hace y se mantiene leal al oficio. De modo que su estadía allí significa un voto de confianza y apoyo a las autoridades, además de un efecto del amor que Úrsula tiene por su trabajo. Incluso, para ejemplificarme cuán endeble se había vuelto la gestión policial, una de las oficiales me dijo: "Estos jefes son un desastre. Si ahora hasta Úrsula se quiere ir, jmirá lo que te digo!".

Vivir en la comisaría implica realizar una serie de atenciones a las instalaciones que Úrsula parece cumplir satisfactoriamente. Esos servicios al conjunto convierten la manera de estar allí de ella, de la de otros posibles interesados como el Turco, quien también coquetea con la idea de permanecer en la comisaría, pero no se instala del modo en que lo hizo Úrsula. Limpiar el baño, hacer la comida, mantener la cocina en orden, conseguir y tener a mano elementos básicos (como aceite, jabón o papel higiénico). La sargento, con su presencia y sus cuidados, le ha dado un sentido doméstico a un espacio laboral y a un edificio que dista por lejos de serlo. En términos generales, no es la única persona que "vive" en la comisaría, cuando esa expresión significa pasar mucho tiempo diario en ese lugar o haciendo tareas vinculadas a él, pero sí la única mujer en esas condiciones y la única que en muchas ocasiones transita ese espacio de trabajo como su hogar. Esto genera responsabilidades y posibilidades diferentes a las que tiene el resto del personal. Por un lado, una serie de actividades domésticas que no son contabilizadas como trabajo pleno. Parte de la negociación implica que puede ser consultada a cualquier hora del día y que está siempre lista para entrar al ruedo laboral si las circunstancias así lo demandan. No sólo no parece verse molesta cuando a la madrugada se le encomienda alguna tarea o se le pide cierta información, sino que le imprime el mismo dinamismo y practicidad que en cualquier otro momento del día.

Por otro lado, tiene un lugar privilegiado para ser observadora directa a toda hora de los sucesos laborales. Suele pasar la información de lo que ocurre desde un turno hacia el siguiente, muchas veces para saciar la curiosidad de sus compañeros/as y otras porque son datos requeridos para diligencias.

Ese lugar privilegiado y la manera serena y "leal" en que lo hace valer es razón suficiente para participar con las recomendaciones principales del armado de la lista de posibles ascensos. Las discusiones más difíciles tienen que ver con los lugares que serán ocupados por suboficiales; Úrsula desenvuelve argumentos sobre los méritos de Fuertes, la mujer que está de ayudante de guardia en el turno noche y que los jefes casi desconocen porque difícilmente trabajen juntos. Pero nada hace por Navata, quien ya se podría haber retirado pero, de común acuerdo con los jefes, continúa en la comisaría. Para Úrsula, Navata ya "está de vuelta, no hace nada más que llevar y traer papeles. Tiene hijas grandes, ya se podría jubilar así como está". Poco puede hacer en la decisión de qué oficiales incluir, donde, parece, se juegan también intereses e intercambios con los titulares de la dependencia. Y aunque ese listado sea sólo una propuesta (con puntajes para cada una de las personas que trabajaron ese año en la comisaría) que pasará por varias instancias donde puede ser modificada, la imagen más cercana y accesible que existe de ella está en la Oficina de Personal.

Tal como adelantamos en el primer apartado, no se trata de la irrupción del amor romántico en el desempeño profesional de Úrsula. Sino en el apego por el trabajo que, en la jerga policial, es señalado como "vocacional". Y en esa colección de atenciones serviciales que ella ofrenda como quien lo hace en su hogar, no sólo para sí misma sino para el conjunto. Finalmente, la "confianza" mutua establecida con sus jefes también deviene como materia 
esencial en las responsabilidades y ventajas profesionales de cada sujeto. Esa confianza es la que habilita usos particulares del espacio, exige tiempo de trabajo extra y consagra la autoridad de Úrsula con respecto a sus compañeros/as de trabajo.

\section{El erotismo en la producción social de la autoridad}

La situación conyugal de quienes trabajan en la comisaría y su consecuente evaluación participa activamente en la conformación de la reputación de cada persona. Los valores que se ponen en juego a la hora de apreciar el desempeño de los/as policías provienen de diferentes experiencias y no se circunscriben a tácticas o elementos de uso estrictamente policial. La vida sentimental, los engaños amorosos, las infidelidades, la estabilidad conyugal están presentes a la hora de examinar la aptitud de sus compañeros/as, de explicar la naturaleza de los méritos conseguidos y de excusar sus faltas. Pero, ¿qué es lo que esto tiene estrictamente que ver con las relaciones de autoridad en la comisaría? Se puede estar en pareja con distintos niveles de formalidad y exhibición de la relación, a partir de lo cual se habilita un prestigio social diferencial. Las mujeres son especialmente examinadas por su estado civil, prestándole especial atención al dato de si aquella persona con quien mantienen el vínculo amoroso o sexual actúa o no en la misma comisaría.

Voy en búsqueda de los oficiales Vanina y Edgardo que están de caminantes en el centro. La encuentro a Vanina en la calle Belgrano, a unos metros de la calle Buenos Aires, en la puerta de un comercio. Cuando le pregunto por Edgardo me dice que se fue a "tirar" un rato porque está muy cansado: "ayer lo hicieron quedar hasta re tarde y hoy lo recargaron desde temprano, le avisó Ximena, bah, lo recargaron para que le haga de chofer a ella. La minita se manejó mal, porque ahora está con todos los humos, entonces lo llamó y le dijo que el titular decía que se tenía que quedar de $\operatorname{cores}^{15}$. Claro, listo, Edgardo bajó para que lo notificaran y lo que tenía que hacer era manejarle el auto a la señorita para que vaya por las escuelas. No estamos para eso, pasa que andá a decirle algo, ahora es la jermu del titular y se piensa que puede hacer cualquiera. Pero así no hay que manejarse, porque hoy estas ahí, pero mañana no te quiero ver por acá". Vanina me cuenta que fue a la escuela de policía junto a Ximena, son de la misma promoción y empezaron a trabajar al mismo tiempo en esta comisaría, y que por eso se tratan y se saludan, pero que no tiene "mucha" relación, y ahora, "desde que Ximena sale con el titular", mucho menos.

La relación entre Ximena y Héctor es conocida por todos/as en la comisaría, aunque no se hable de ella abiertamente. Es innegable que, para los/as observadores/

\footnotetext{
15 El servicio de CoRes (Compensanción Regular de Servicio) corresponde a las horas extra.
}

as, la diferencia de jerarquías entre estos amantes tiene un peso especial (él tiene la máxima jerarquía y ocupa el lugar de mayor autoridad, y ella tiene el grado de ingreso con apenas dos años de trabajo en la institución), a lo que se suma la distancia etaria de unos 25 años. Las argumentaciones de compañeros/as de trabajo sobre el aumento de responsabilidades de Ximena, su libertad para comunicar órdenes y disponer de personal e incluso las llegadas tarde van en dirección a la relación amorosa que vive. De manera que quedan en el olvido las capacidades laborales de esta oficial. A pesar de que las recargas horarias se hacen casi a diario, en la conversación con Vanina registrada más arriba, lo que convirtió en excepcional a esta comunicación fue el modo y no la recarga por sí misma.

Vanina supone que debe ser condescendiente con Ximena porque es la "jermu del comisario" y, al contrario de otras mujeres con las que las autoridades de la comisaría mantienen o mantuvieron relaciones íntimas, ella "sabe sacar su beneficio" haciendo pesar ese lugar privilegiado en el que está. Una de las nociones que están presentes entre los/as nativos/as es que las relaciones heterosexuales son un bien a intercambiar entre dos personas, pero quien sale beneficiado automáticamente de ella es el varón involucrado. En esta idea, suprimen el deseo y el goce en la sexualidad experimentado por la mujer. Consideran que para que haya intercambio justo, las mujeres deben obtener otro beneficio lateral que puede consistir en el cobro de horas extra, poder de decisión, días de franco, vacaciones o "una oficina".

Definitivamente, Edgardo es notificado por su recargo, trabaja más horas de lo que esperaba, tiene sueño y ganas de volver a su casa. Considera que tiene que hacerlo porque hay una autoridad informal que pesa mucho más que las demás, pero tiene la certeza de que esa autoridad es momentánea. Pronto Ximena será apenas una más de todas las amantes que Julio ha tenido, volverá a ser simplemente la oficial que ingresó a la institución al mismo tiempo que él y tendrá la desventaja de haber quebrado los códigos del compañerismo: "porque si me lo dice de buen modo, yo igual me quedo, pero me llama de su celular haciéndose la cocorita".

El "beneficio" parece ser un bien disponible en las relaciones. Y si de un lado hay una "mujer viva" para hacerse de él, del otro hay un "mujeriego" cuya debilidad frente a los encantos femeninos se traduce en un uso flexible del poder. Noté esta clasificación nativa en una entrevista con el oficial de servicio, cuyo relato narraba una situación reciente en la que él trató de distribuir el personal entre los puestos a cubrir, lo cual desembocó en una discusión con las tenientes Salerno y Demare que se resistían a subir al móvil policial.

El teniente primero me dijo que ya le había pasado otras veces eso de tener que discutir porque las chicas no quieren subir al móvil, entonces fue a 
la oficina del segundo jefe y le dijo: "ahí están de nuevo, arreglate vos. Fijate quién se queda y quién sube y después me avisás, pero alguien tiene que subir, no tengo más gente". Me asegura que tomó esa determinación porque "ya pasó esto, yo las ubico donde necesito gente porque acá están amontonadas y porque además tienen que hacerlo, pero después se meten ahí adentro [la oficina del jefe], le charlan un poco y lo convencen enseguida. Entonces, si él las va a dejar hacer cualquier cosa, yo ni me gasto en discutir, porque ellas enseguida sacan algún beneficio. $Y$ este tarado con tal de volteárselas les dice que sí a todo".

En este relato, el oficial de servicio considera que al sucumbir a los atractivos femeninos, los jefes ponen en duda su capacidad profesional y su libertad de decisión.

En otras situaciones la conformación de parejas tiene una recepción diferente, al mismo tiempo que los/as involucrados/as son vistos/as de modo distinto. La relación entre la oficial Nuria Martínez y el sargento Víctor Fuentes fue, desde el inicio, conocida y festejada por la mayor parte de los miembros de la comisaría.

Son un poco más de las 10 de la noche, ya todas las cuadrículas están volviendo a salir. Como todos los viernes, hoy hay operativo de nocturnidad en apoyo de la comisaría primera, por lo que hay más móviles que de costumbre. Cruzo el patio y veo una de las camionetas maniobrando; al mirar dentro de ella, la distingo a Nuria sentada en el asiento del acompañante. Me saluda con la mano y me acerco a darle un beso. Víctor es quien maneja. Víctor apaga la camioneta, baja, me saluda y se pone en la puerta del gabinete de investigaciones a charlar con los oficiales de calle. Yo me apoyo en la ventanilla y cuchicheo con Nuria, sorprendida porque suele contarme que no hace muchas cores porque no tiene una buena relación con el jefe de calle, y es él quien las autoriza. Habitualmente le ofrecen hacer cores a la tarde o a la mañana, pero eso implica que también las haga de caminante en la calle y se cansa demasiado.

Me dice que Víctor "arregló" con Juan Ibarra, el jefe de calle, para hacer las cores juntos, y lo bueno de hacerlas de noche es que se meten varias horas juntas y no repartidas de a cuatro, como en la semana. Además, aprovecha para pasar la noche con su novio, dado que ninguno de los dos dispone de casa propia, es una buena estrategia para enmendar la falta. Le hago chistes sobre la baja productividad que tendrá esa cuadrícula esta noche. Ella se sonríe con picardía y me dice que eso espera.

Su hija estuvo enferma esta semana, pero la tuvo que llevar al médico la mamá de Nuria porque a la mañana ella está haciendo adicionales, lo cual también llama mi atención. Hasta la semana pasada Nuria sólo tenía un adicional en un hospital dos veces por semana, que al ser una institución del gobierno de la provincia, tardan mucho en pagarle. Pero esta semana empezó con un banco privado, por el que le pagan semanalmente porque los bancos pagan por adelantado. Nuria está contenta porque su sueldo va a aumentar bastante este mes, y desde que empezó a trabajar nunca había podido tener un banco. Le pregunto cómo accedió a ese adicional y me responde "porque es el banco que hace Víctor, y como él ahora está haciendo un curso en La Plata para tener la tecnicatura en seguridad, tiene que viajar dos veces por semana y yo le cubro esos días, de ahora hasta fin de año".

Nuria intentó por varios medios ingresar al circuito de las horas extra menos costosas físicamente o con los horarios más acomodados a sus necesidades, pero le fue muy dificultoso. Quienes tienen mayor libertad de elegir las horas extra son aquellos/as que disfrutan de un vínculo más estrecho con los/as encargados/as de administrarlas o algunos años de antigüedad en el trabajo. Sin embargo, el estar en pareja con Víctor abrió la puerta hacia un circuito nuevo, donde no sólo dispone de una mayor cantidad de horas para trabajar sino que además no carga con el prejuicio corriente de aquellas mujeres que aceptan guardias de nocturnidad con varones. No es tachada ni de "tira vigis" ni de "mujer ingenua"16 que es "usada" por un varón, sino que es sencillamente la pareja de Víctor, "un tipo trabajador y responsable" a quien no se le conocen aventuras amorosas con otra policía mujer. Esta relación la aleja a Nuria del juego de propuestas, coqueteos, piropos, asedios, competencias y comentarios inquisidores acerca de sus comportamientos y deseos sexuales. A diferencia del lugar que tiene Ximena, nadie supone que lo que hay en el vínculo de Nuria con Víctor es una suerte de intercambio interesado, ni un sentimiento efímero. La relación que hay entre ellos responde a los cánones más tradicionales de lo que se espera de un varón y una mujer: seriedad y formalidad que desembocará en la conformación de una familia.

El camino sentimental, y en consecuencia laboral, de Ximena le permitió ubicarse en un lugar de mucho poder, pero con una base de legitimidad endeble. Lo cual se veía detrás de la hipótesis de su compañera de que esa conquista era momentánea y se desvanecerá pronto. Nuria, envuelta en una relación íntima que es considerada por sus compañeros/as diferente a la descrita anteriormente, también accedió a un nivel mayor de capacidad para tomar decisiones sobre los tiempos,

\footnotetext{
16 Son dos variantes de las mujeres que son consideradas "putas": o bien tienen un papel activo y son conscientes de lo que hacen (las "tira vigis"), o bien son mujeres engañadas por las habilidades de los varones y se les adjudica un papel completamente pasivo y desinteresado en el sexo, aunque condescendiente.
} 
lugares y horarios de su trabajo.

Una última alternativa al modo en que se presentan las parejas en la producción de poder y su legitimidad, es aquella donde las pasiones de la policía mujer no se dirigen a ningún varón del mismo espacio de trabajo.

Caminamos con la oficial Vanina Velásquez por una de las calles del centro, anda muy poca gente y varios de los negocios están todavía cerrados. Me cuenta sobre las últimas recargas de los fines de semana, las llamadas de atención por no llevar puesto el chaleco antibalas y la posterior discusión con el titular: "el titular es un estúpido, a veces me dice 'ah, ya andás gritando, a vos querida... te hace falta un novio'. Mirá lo que me dice el tipo, ¡es el titular! Como si fuera un problema mío, que estoy mal. Yo lo miro pensando 'yo cojo tres veces más de lo que vos cogés en todo el año', pero no le puedo decir nada, porque soy una bocona y se me sale la cadena y puedo terminar diciéndole cualquier cosa. Todo el tiempo me dicen 'ique humor que tenés, querida!'.

Vanina se pone eufórica durante el relato, se entusiasma y grita remedando la situación original. “¿Como si las cosas que decís fueran sólo por tu mal humor?", le digo con tono de pregunta, pero sentido de afirmación. Ella sigue, "claro, me dan ganas de decirle: ¿qué le molesta? ¿Que no me agache? Yo me agacho con quien quiero, y antes de agacharme con usted...' [nos reímos] Es que es cierto"

Vanina con frecuencia recibe comentarios que la enuncian como "una loca", que "le falta un novio" o que "duerme demasiado"17. En general ella contesta remarcando su actividad sexual dinámica y su alta productividad en el cortejo. De todas formas, lo que más se destaca en su discurso es la capacidad que detenta para elegir con quien estar o no, ya que ni las circunstancias del trabajo ni las relaciones jerárquicas la doblegan para aceptar invitaciones de los varones de la comisaría orientadas a tener un vínculo sexual o amoroso. Vanina pone de manifiesto que sus pasiones no se desenvolverán en el espacio de la comisaría, no porque no tenga la posibilidad, sino porque no lo desea. En esa actitud eróticamente desinteresada hacia policías varones, hay también una intención de debilitarlos, los ignora como hombres capaces de atraerle. Y, sobre todo, le resta importancia a esa imagen de peligro sexual con la que los varones se identifican frente a sus compañeras. Las quejas y demandas por asuntos profesionales que hace Vanina son, para sus compañeros y jefes, muestras de la falta de satisfacción sexual.

\footnotetext{
17 Que, por contrapartida, significa que por las noches no tiene relaciones sexuales.
}

Esta maniobra para reducir el poder de los varones de la comisaría, especialmente de quienes tienen lugares privilegiados de autoridad, permite como consecuencia la búsqueda de estabilidad laboral propia. En un escenario desventajoso para Vanina, caracterizado por ser una de las últimas personas en haber llegado a la comisaría, joven (y, por ello, con poca experiencia), con el más bajo de los grados jerárquicos y con una tarea diaria lateral de poca responsabilidad, el despliegue de la indiferencia sexual dirigida le ayuda a recuperar autonomía para moverse en el trabajo.

Vanina me cuenta una diferencia de criterios con el jefe de calle "González me dijo que lo llame para avisarle lo que hago y que en la guardia estaba su número. Pero cualquiera, mirá que lo voy a andar llamando. El teléfono es para uso personal, yo no tengo ganas de que me anden llamando, ¿y si no tengo ganas de atender? ¿Y si no me anda el teléfono? Ellos te tienen que proveer de todas las herramientas para trabajar, ellos me tendrían que dar un handy para salir a la calle. Yo no le escribo mensajes de texto un carajo, no sos ni mi macho, ni mi marido y ni mi novio ¿por qué te voy a andar llamando todo el tiempo?"

Las metáforas de las relaciones íntimas habilitan acciones en el trabajo que se descomponen cuando esas relaciones figuradas no existen. Marcar la inexistencia de noviazgo, aventura amorosa o matrimonio, le sirve a Vanina para agenciarse seleccionando aquellos gestos de respuesta al control jerárquico que realizará. Evita, de este modo, una sumisión permanente a la autoridad de los otros y discute el precepto que indica que el poder legítimo se acumula y ejerce de un único modo.

La dirección y exhibición de las relaciones amorosas trabajadas en este apartado, a través de las que estas mujeres utilizan o se enfrentan a las reglas estructurales del trabajo en la policía, relevan estrategias distintas de acumulación de poder. La femineidad se informa en estos diálogos que legitiman varias formas de poner en acto la experiencia de ser mujeres. Al contrario de la hipótesis de la desfeminización, lo que acá vemos es el uso estratégico de rasgos -particulares en cada casoconsiderados bienes femeninos válidos para agenciarse y conseguir estabilidad profesional o ascenso económico a través de las relaciones. En esta instancia es apropiado volver sobre las consideraciones de Cornwall y Lindisfrarne (1994) en las que las configuraciones de género muestran matices, incluyen diferencias, son cambiantes y, lejos de constituirse como realidades normativas estables en la sociedad, son procesos que autorizan las disputas de sentidos. Finalmente, la heteroafectividad es una característica relevante en este campo de seducciones y poder, juega como una frontera simbólica a través de la que las personas ingresan o escapan de esta particular dinámica de construcción de autoridad. No significa que no exista, en este campo, referencias y experiencias 
homoeróticas, sino que inicialmente estas no cuentan con la misma dinámica de participación abierta en el acopio y legitimación de poder.

\section{Valoraciones profesionales y transversalidad de género}

La teniente Adriana Ordóñez es parte de la última cohorte que ingresó con el "viejo" ordenamiento legal y administrativo, es decir, antes de las reformas normativas del año 2004 que unificaron los dos escalafones. Ordóñez hizo la formación policial básica para oficiales de policía y se recibió como oficial ayudante. Actualmente es la mujer con mayor grado jerárquico en la comisaría, pero esto combina la formalidad de los nombramientos de la institución con la distinción que -aunque obsoleta en la normativa- sigue operando en la práctica. Con esto me refiero a que si bien hay otras mujeres que en la actualidad tienen también el grado de teniente, formaban parte del viejo escalafón de suboficiales, cosa que las distingue de la situación de Adriana.

La Oficina de Causas es el lugar donde generalmente trabaja Adriana, se encarga de seguir los expedientes que envían desde el juzgado, adjuntándoles declaraciones, informes o fotografías pedidos desde el ámbito judicial. En la oficina también trabajan Nahuel, Ramiro, Vanesa y Marina, pero es Adriana quien organiza las tareas de cada uno/a y a quien se la consulta por todo lo que allí ocurre. Pero además de las responsabilidades que son parte de la órbita de esta oficina, Adriana es consultada desde distintos rincones de la dependencia policial, especialmente sobre asuntos legales, jurisprudencia, normativas y administración policial. Es que cursó durante cuatro años en la facultad de derecho antes de ingresar a la academia policial, cosa que la distingue como "casi abogada" para sus compañeros/as de trabajo.

Contagiada por ese respeto que le proporcionan las personas que trabajan con ella, yo misma en más de una ocasión le pregunté dónde podía hacer las entrevistas y observaciones de campo. Esa era una consulta que, por cortesía, yo elegía hacer para no obstaculizar el trabajo diario de los/as policías. El comisario que me autorizó inicialmente para hacer el estudio allí me avisó, desde el primer día, que durante su ausencia podía consultar "cualquier cosa" con Ordóñez, debido a que ella quedaba a cargo. No obstante, Adriana se mostraba ajena a ese lugar en el que mis preguntas la ponían, respondiéndome con evasivas: "yo no sé", "hacé como quieras", "yo no tengo nada que ver".

Aunque discursivamente no asuma el lugar de poder consolidado que los jefes refieren, presencié situaciones que mostraban la libertad para decidir sobre cuestiones laborales de esta teniente. Una tarde de sábado, conversábamos con el comisario que queda a cargo los fines de semana, cuando Ordóñez le avisó que no podía entregarles una nota a las oficiales que estaban haciendo guardias en la zona céntrica de la localidad porque no contestaban el teléfono y porque, además, ella misma había constatado que no estaban en la esquina que debían. Ortega, el comisario a cargo, se vio rápidamente desbordado por la situación, cosa que se notaba en la falta de ideas para solucionar el problema.

Pasan unos 15 minutos más cuando entra a la oficina la oficial Sosa, una de las "caminantes" que no encontraban, llega con actitud insegura y un tono muy bajo de voz. Inmediatamente entra Adriana a la oficina y discuten los tres frente a mi, que permanezco muda en una silla. Adriana dice que las estuvo buscando, que no están en su lugar y no responden al teléfono. Sosa con timidez dice que ella estaba caminando, que no estaba parada en un lugar porque su QTH ${ }^{18}$ tiene varias cuadras. Le preguntan por sus dos compañeras y ella responde que no sabe, que ella tiene su QTH sola. Las miradas de la teniente y el capitán me da a entender que no le creen, pero, de todas maneras, Ortega intenta diluir la discusión pidiéndole que firme la nota para la que la buscaban inicialmente. Ordóñez no tiene intenciones de olvidar ese detalle y les dice a ambos que "va a tener que escribir", en franco tono de amenaza. En este caso, "escribir" se refiere a hacer una nota de sanción para Sosa.

La discusión se transporta hacia la guardia y luego hacia el fondo del edificio, donde está el patio, alejado de las oficinas. Ortega no participa de la controversia, sino que se queda charlando y más tarde sale de recorrida por los puntos del operativo de rutina que está en funcionamiento ese sábado (casi como todos los fines de semana).

Las tres oficiales que debían estar de "caminantes" en el momento en que Ordóñez las buscaba, recibieron -por esa ausencia- una sanción disciplinaria de dos días. Eso significa que a fin de mes se les descuenta de su sueldo dos días de trabajo (más allá de que deberán trabajarlos de todas formas).

"Escribir" es mucho más que una actividad de registro, creatividad o administración. Es, en este escenario, una habilidad muy bien valorada por ser poco frecuente y por el ejercicio intelectual que requiere. La escritura es una herramienta a través de la cual se determina una verdad, porque registra un relato sobre los hechos, y -en algunos casos, como el recién comentado aquí- se propone una sanción. Para "escribir" sobre la actuación de un/a compañero/a, Adriana cuenta con una aprobación tácita de las autoridades y con la creencia en sus capacidades para observar y evaluar de los demás miembros de la comisaría. Confían en que ella tiene no sólo el conocimiento profesional para hacerlo, sino también el

\footnotetext{
18 QTH es la sigla con la que denominan una ubicación geográfica (que puede ser un punto fijo o un tramo) en la que realizan la vigilancia o custodia.
} 
criterio justo (para no sobredimensionar las faltas) y la autoridad moral.

La guardia es el sitio donde esperan los papeles que explican, muy resumidamente, por qué se dispone una sanción para cada una de las oficiales y allí se reserva un lugar para la firma de las mismas. Esa "notificación" fue efectivamente aceptada por las sancionadas y ellas, sin desconocer que cometieron una falta, aseguran que la motivación para esa sanción es simplemente que Adriana no las "quiere". Y aún en esa explicación, también existe la certeza de que la teniente tiene el apoyo y la libertad para tomar decisiones antipáticas y de relevancia. Por contrapartida a los casos anteriores, aquí ya no son esos amplios tipos de relación y comunicación que englobamos en la noción de amor los que participan, sino su contratara. Una suerte de desprecio, antipatía o rechazo sentimental se vuelve útil para explicar, desde un punto de vista nativo, las regulaciones del campo laboral. La falta de afecto toma relevancia como fundamento y orientación del uso de poder entre compañeras de trabajo.

Decidí incluir este caso para mostrar una de las situaciones donde aquello que sustenta socialmente la autoridad de una mujer en la policía está más allá del género. La posición privilegiada que tiene Adriana allí se apoya en una capacidad profesional que puede ser detentada tanto por varones como por mujeres de manera indistinta. Sus conocimientos académicos sobre derecho y su importante grado jerárquico la convirtieron en una interlocutora válida para jueces/zas y fiscales -personajes respetados y temidos por policías-, otras fuerzas de seguridad y otras direcciones de investigaciones de la institución (narcotráfico, delitos complejos, asuntos internos, etc.). En cambio, en las situaciones relatadas en el punto anterior, el rol social al que se vincula a las mujeres es central en la construcción de relaciones de poder. Allí el comportamiento erótico y la búsqueda sexual juega un papel preponderante en las formas de explicar la autoridad (es decir, el poder legítimo), marcando una evidente distinción social entre varones y mujeres. Mientras se asocian ciertos comportamientos y deseos sexuales a varones, se reservan otros diferentes para mujeres. Y la existencia efectiva o potencial (a través de metáforas o ejemplos contrafácticos) de relaciones amorosas entre ellos/as explica el poder que tienen algunas mujeres para dar o enfrentar consignas laborales.

Pero en esta última situación, quiero remarcar dos cuestiones. La primera de ellas, enunciada en el párrafo anterior, indica que si bien las expresiones de género no son ignoradas en la policía, existen algunas situaciones donde el poder se constituye sobre capacidades que pueden ser ejercidas tanto por varones como por mujeres. Sin embargo, el ejemplo muestra que si bien el amor pasa a segundo plano, continúa estando presente en la fundamentación del ejercicio del poder. Las explicaciones afectivas no quedan anuladas en ninguna de las situaciones analizadas, aunque en todas ellas ocupan lugares distintos. El otro tema es que Adriana, al hacer ejercicio de su autoridad, también realiza un abandono de marcas clásicas de la femineidad sin que eso signifique una masculinización del rol. Se trata de, en diálogo con el análisis de Susana Durão sobre la policía en Portugal (Durão, 2008), cierto hibridismo genérico en el que conviven comportamientos y rasgos que no son ni exclusivamente femeninos ni exclusivamente masculinos. Esta es una situación donde se ve cómo algunas fuentes de legitimidad personal tienen una presencia transversal con respecto al género, sin establecer distinciones entre mujeres y varones.

\section{Reflexiones finales}

Las modificaciones cuantitativas recientes en el reclutamiento femenino es el punto de partida de este trabajo porque es un tema de relevancia en el espacio social estudiado, concentra discusiones acerca de la división sexual del trabajo y es visto como una particularidad de la policía bonaerense de la última década. Sin embargo, en el desarrollo del trabajo vimos cómo se experimentan diariamente las relaciones de poder, haciendo énfasis exclusivo en los modos legítimos de ejercicio de la autoridad por parte de las mujeres.

La descripción de los casos concretos permite vincular clivajes sociales distintos (Melhuus y Stølen, 2005): jerarquía, género, antigüedad en la institución, nivel educativo, generación, estado sentimental. Conviven desigualdades producidas por cada una de esas caracterizaciones, que derivan en posibilidades de construcción de prestigio personal en la comisaría. El poder de las mujeres se caracteriza, entonces, por el modo en que se conjugan y significan esas distinciones sociales (algunas más próximas a lo estrictamente institucional). En algunos casos, las relaciones de género condicionan fuertemente el modo en que se legitiman las autoridades. Con esto quiero decir que las relaciones laborales se explican, desde la perspectiva de los sujetos, por rasgos generales que identifican a mujeres o varones. Esto pasa, por ejemplo, en el intento de explicar la manera de actuar de las mujeres en el campo laboral de acuerdo al modo de desenvolverse en el terreno de su sexualidad. Pero, también he incluido un último ejemplo donde el hecho de ser o no una mujer no aparece para revelar a qué se debe la solidez de la autoridad. En ese caso, las competencias intelectuales cultivadas en la universidad y el grado jerárquico formal motorizan gran parte de las relaciones de confianza que sostienen a esa policía mujer.

Con la reconstrucción de situaciones particulares puede apreciarse el modo en que se efectúa el poder en vínculos entre mujeres y entre mujeres y varones (cuando quienes dan las órdenes son varones y cuando son mujeres). En este sentido, se ve cómo las concepciones de género no siempre significan sumisión, sino que también se hace uso del lugar de las mujeres para agenciarse y actuar sobre la realidad. La idea de que las mujeres pueden 
"sacar ventaja" de algunas relaciones amorosas, les permite acceder a lugares de poder. Del mismo modo que el género no tiene siempre el mismo significado en ese abanico de beneficios sociales disponibles, la autoridad no significa una única cosa ni se construye con las mismas estrategias. Es variable de acuerdo a características personales y relacionales de los individuos. No obstante, la autoridad no es un terreno sin límites y, en este trabajo, mostré los modos más significativos de cultivarla y sostenerla en la estación policial.

El ejercicio de la autoridad por parte de las mujeres en la policía bonaerense está asociado a la dimensión que llamé, de modo figurativo, amor. Las relaciones, sentimientos y experiencias afectivas (amistosas, confidenciales, eróticas, matrimoniales, etc.) ocupan un lugar importante en la constitución y legitimación de la autoridad de mujeres. Se las apunta tanto para indicar la efectividad y naturaleza del poder, como para mostrar procesos de desintegración del mismo. Por ejemplo, se pone de manifiesto cuando gracias a ese plus afectivo algunas policías mujeres intervienen en la confección de la "lista de ascensos", acceden a mejores horarios o tipos de servicios laborales, al uso de oficinas mejor acondicionadas o a la posibilidad de aplicar sanciones disciplinarias a otros/as policías. Definitivamente, para que la autoridad se consagre en estos casos, requiere de una dedicación específica que invoca al mundo de las emociones y sentimientos personales que así como obligan a actuar en una dirección, también constituyen una estrategia o atajo en el camino profesional.

\section{Agradecimientos}

Bernal, 21 de octubre de 2011

Agradezco las discusiones brindadas sobre una versión preliminar de este trabajo por los/as integrantes del Grupo de Estudios de Policía y Fuerzas de Seguridad (IDES), José Garriga, Mariana Galvani, Tomás Bover, Mariano Melotto, Agustina Ugolini, Paul Hathazy y, especialmente, las atentas recomendaciones de Sabina Frederic. También agradezco los aportes de quien evaluó de forma anónima para la revista, cuya lectura ayudó a enriquecer el texto.

\section{Bibliografía citada}

Arteaga Botello, N. 2000. El trabajo de las mujeres policías. Revista El Cotidiano, volumen 16 (número 101): 74-83.

Bourdieu, P. 1998. El sentido práctico. Minuit, Madrid.

Bover, T. y Calandrón, S. (2009). De- Formar a la Fuerza. Un análisis de las reformas policiales en los espacios de formación profesional. Ponencia presentada en la VIII Reunión de Antropología del Mercosur, Universidad Nacional de San Martín, Buenos Aires.

Calandrón, S. y Galeano, D. (en prensa). La “Brigada
Femenina". Incorporación de mujeres a la Policía de la Provincia de Buenos Aires (1947-1955). Barreneche, O. y Salvatore, R. (comp.). El delito y el orden en perspectiva histórica. Nuevos aportes a la historia de la justicia penal y las instituciones de seguridad en Argentina. Prohistoria, Rosario.

Cornwall, A. y Lindisfrarne, N. 1994. Dislocating masculinity: gender, power and antrophology. Routledge, Londres.

Durão, S. 2004. Quando as mulheres concorrem e entram na policía: a óptica etnográfica. En Revista Etnográfica, volumen III (1): 57-68.

Frederic, S. 2008. Los usos de la fuerza pública: debates sobre militares y policías en las ciencias sociales de la democracia. Universidad Nacional de General Sarmiento, Los polvorines / Biblioteca Nacional, Buenos Aires.

Garriga Zucal, J. 2010. Se lo merecen. Definiciones morales del uso de la fuerza física entre los miembros de la policía bonaerense. Cuadernos de Antropología Social, núm. 32: 75-94.

Hagen, A. 2005. O trabalho policial: estudo da polícia civil do Estado do Rio Grande do Sul. Tese Pós-Graduacao en Sociologia, Universidad Federal do Rio Grande do Sul.

Martin, S. 1980. Breaking and entering: policewomen on Patrol. University of California Press, Berkeley.

Melhuus, M. y Stølen, K. 2008. Introducción. Melhuus, Marit y Stølen, Kristi (comps.). Machos, putas, santas. El poder imaginario de género en América Latina. Antropofagia, Buenos Aires.

Renoldi, B. 2007. El olfato. Destrezas, experiencias y situaciones en un ambiente de controles de frontera. Anuario de Antropología 2006, IDES. Editorial Antropofagia, Buenos Aires.

Renoldi, B. 2010. Persona, agencia y estado: rutinas de instrucción judicial en el proceso federal argentino. Cuadernos de Antropología Social, núm. 32: 95-120.

Scott, J. 1996. El género: una categoría útil para el análisis histórico. Cangiano, M. y Dubois, L. (dir.). De mujer a género. Teoría, interpretación y práctica feminista en las ciencias sociales. CEAL, Buenos Aires.

Suárez de Garay, M. 2006. Los policías: una averiguación antropológica. ITESO: Universidad de Guadalajara, Guadalajara.

Weber, M. 1996. Economía y Sociedad: esbozo de sociología comprensiva. Fondo de Cultura Económica, México DF. 